\title{
Effect of roxithromycin on airway responsiveness in children with bronchiectasis: a double-blind, placebo-controlled study
}

\author{
Y.Y. Koh, M.H. Lee, Y.H. Sun, K.W. Sung, J.H. Chae
}

Effect of roxithromycin on airway responsiveness in children with bronchiectasis: $a$ double-blind, placebo-controlled study. Y.Y. Koh, M.H. Lee, Y.H. Sun, K.W. Sung, J.H. Chae. (C) ERS Journals Ltd 1997.

ABSTRACT: Increased airway responsiveness (AR) is frequently associated with bronchiectasis. Roxithromycin is a new semisynthetic macrolide antibiotic that also has anti-inflammatory activities. This study was designed to see whether roxithromycin could favourably alter the degree of $A R$ in patients with bronchiectasis and increased AR.

Twenty five children with bronchiectasis, who had an increased AR (defined as a provocative concentration of methacholine causing a $20 \%$ fall in forced expiratory volume in one second (FEV1) $(\mathrm{PC20})<25 \mathrm{mg} \cdot \mathrm{mL}^{-1}$ evaluated by the dosimeter method), were randomized, double-blind into two parallel groups. Thirteen of the children were treated with roxithromycin $\left(4 \mathrm{mg} \cdot \mathrm{kg}^{-1}\right.$ b.i.d.) for 12 weeks and 12 received placebo. FEV1, sputum purulence and leucocyte scores were assessed every 3 weeks. To estimate AR, high-dose methacholine challenge tests were performed before and after treatment. On the dose-response curve to methacholine, PD20 and maximal response (two indices of AR) were measured.

Changes in FEV1 were not observed during the course of the study in both groups. A significant improvement in sputum features was noted after 6 weeks of treatment in the roxithromycin group. After 12 weeks of roxithromycin therapy, the geometric mean (range of $1 \mathrm{SD}$ ) of provocative cumulative dose producing a $20 \%$ fall in FEV1 (PD20) increased significantly $(p<0.01)$ to $169.2(83.2-344.2)$ breath units (BU) (1 BU denotes one inhalation of $1 \mathrm{mg} \cdot \mathrm{mL}^{-1}$ methacholine) and the mean \pm SD of maximal response decreased significantly $(\mathrm{p}<0.01)$ to $32.5 \pm 6.8 \%$, as compared with the initial values (PD20 87.1 (47.3-160.4) BU; maximal response 40.9 $\pm 7.4 \%$ ). No significant changes in either parameter were observed in the placebo group.

Our results indicate that roxithromycin may decrease the degree of airway responsiveness in patients with bronchiectasis and increased airway responsiveness. Further study is necessary to determine the mechanism by which roxithromycin reduces airway responsiveness in bronchiectasis and its clinical impact.

Eur Respir J 1997; 10: 994-999.
Dept of Pediatrics, College of Medicine, Seoul National University, Seoul, Korea.

Correspondence: Y.Y. Koh

Dept of Pediatrics

Seoul National University Hospital

28 Yongon Dong

Chongno $\mathrm{Ku}$

Seoul 110-744

Korea

Keywords: Airway responsiveness bronchiectasis

maximal response

provocative concentration

roxithromycin

Received: July 161996

Accepted after revision December 101996

This study was supported by grant No. 294-112 from the Seoul National University Hospital Research Fund.
Bronchiectasis is a chronic lung disease characterized by permanent dilatation of the bronchi, loss of connective tissue and fibrosis [1]. The key pathogenic factors are postulated to be chronic bronchial sepsis and persistent airway inflammation $[2,3]$. Airway hyperresponsiveness (AHR), the hallmark of bronchial asthma, is frequently associated with bronchiectasis [4-6]. Although the mechanism underlying AHR in bronchiectasis is not completely understood, AHR may play a part in the pathogenesis of bronchiectasis by reducing the efficiency of respiratory clearance mechanisms and thereby promoting microbial colonization and inflammation [2].

The recent trend in the treatment of bronchiectasis is long-term antibiotic therapy to decrease the inflammatory load in the bronchial tree. This may interrupt the "vicious" cycle of infection and inflammation [7]. Studies with higher dose and longer term antibiotics have shown better clinical response and reduction of lung inflammation for longer periods after cessation of treatment, in patients with chronic bronchial infection [8-10].

In the course of long-term antibiotic therapy, changes in airway responsiveness (AR) have seldom been studied. KeLLY et al. [11] have shown that a 3 week course of amoxycillin reduced the degree of AR in patients with bronchiectasis. Recently, some of the macrolide antibiotics, such as erythromycin and roxithromycin, have been shown to be effective in reducing AHR in bronchial asthma $[12,13]$. This prompted us to assess the effects of these drugs on the increased AR in bronchiectasis. In this study, roxithromycin was chosen rather than erythromycin, because the former is more potent than the latter in terms of anti-inflammatory action [14], which is presumed to be one of the mechanisms in reducing AHR. The purpose of this study was to determine whether roxithromycin could reduce the degree of AR in bronchiectasis. To test this hypothesis, we conducted a double-blind, 
placebo-controlled study of the effect of 12 weeks of roxithromycin on the degree of AR in children with clinically stable bronchiectasis and increased AR. In the last decade, it has been recognized that AHR has two distinct components: firstly, an increased sensitivity of the airways as shown by a leftward shift of the doseresponse curve, e.g. decreased provocative concentration of agonist producing a $20 \%$ fall in forced expiratory volume in one second (FEV1) (PC20) [15]; and, secondly, excessive airway narrowing as reflected by an elevated or absent maximal response plateau [16]. It can be argued that the latter is clinically a more relevant component of AHR than the former per se because it reflects the potential severity of airways obstruction in the individual patient [17]. Therefore, we measured not only bronchial sensitivity but also maximal response on the dose-response curve to methacholine, before and after roxithromycin treatment.

\section{Materials and methods}

\section{Subjects}

Twenty five bronchiectatic children (14 boys and 11 girls, with a mean age of $13 \mathrm{yrs}$ ) with an increased AR completed this study (table 1). The diagnosis of bronchiectasis was based on clinical features and was confirmed by computed tomography, with bronchography when necessary. Among 63 children with bronchiectasis who had been followed up at our clinic and were old enough to perform pulmonary function tests, 27 (43\%) were found

Table 1. - Baseline characteristics of study population

\begin{tabular}{|c|c|c|c|}
\hline & Total & $\begin{array}{l}\text { Roxithro- } \\
\text { mycin } \\
\text { group }\end{array}$ & $\begin{array}{l}\text { Placebo } \\
\text { group }\end{array}$ \\
\hline Subjects $\mathrm{n}$ & 25 & 13 & 12 \\
\hline Sex M/F & $14 / 11$ & $7 / 6$ & $7 / 5$ \\
\hline Age yrs\# & $13.1 \pm 2.6$ & $13.3 \pm 2.5$ & $12.9 \pm 2.6$ \\
\hline Height $\mathrm{cm}^{\#}$ & $146 \pm 12$ & $148 \pm 13$ & $144 \pm 12$ \\
\hline Weight $\mathrm{kg}^{\#}$ & $36.7 \pm 8.5$ & $37.1 \pm 9.0$ & $36.3 \pm 8.2$ \\
\hline \multicolumn{4}{|l|}{$\begin{array}{l}\text { Cause of bronchi- } \\
\text { ectasis } \mathrm{n}(\%)\end{array}$} \\
\hline Measles & $1 \quad(4)$ & $1 \quad(8)$ & 0 \\
\hline Tuberculosis & $5(20)$ & $3(23)$ & $2(17)$ \\
\hline Ciliary dyskinesis & $6(24)$ & $3(23)$ & $3(25)$ \\
\hline Unknown & $13(52)$ & $6(46)$ & $7(58)$ \\
\hline $\begin{array}{l}\text { Positive skin- } \\
\text { prick test } \mathrm{n}(\%)\end{array}$ & $9(36)$ & $4(31)$ & $5(42)$ \\
\hline Asthma n (\%) & 7 (28) & $3(23)$ & $4(33)$ \\
\hline \multicolumn{4}{|l|}{$\begin{array}{l}\text { Methacholine } \\
\text { challenge test }\end{array}$} \\
\hline PD20 BU & $\begin{array}{c}82.7 \\
(41.8-163.7)\end{array}$ & $\begin{array}{c}87.1 \\
(47.3-160.4)\end{array}$ & $\begin{array}{c}74.2 \\
(36.6-150.4)\end{array}$ \\
\hline$\Delta \mathrm{FEV}_{1, \max } \%^{\#}$ & $40.9 \pm 8.7$ & $42.2 \pm 8.3$ & $39.6 \pm 9.3$ \\
\hline FEV1 \% pred $\#$ & $83 \pm 7$ & $83 \pm 6$ & $84 \pm 7$ \\
\hline
\end{tabular}

\#: mean \pm SD. $*$ : geometric mean, and range of 1 SD in parenthesis. M: male; F: female; PD20: provocative cumulative dose producing a $20 \%$ fall in FEV1: BU: breath unit (1 BU denotes one inhalation of $1 \mathrm{mg} \cdot \mathrm{mL}^{-1}$ methacholine); $\triangle \mathrm{FEV} 1$, max: maximal response to methacholine expressed as the percentage fall in FEV1; FEV1: forced expiratory volume in one second; \% pred: percentage of predicted value. to have an increased $\mathrm{AR}$, defined as a $\mathrm{PC} 20<25 \mathrm{mg} \cdot \mathrm{mL}^{-1}$ evaluated by the dosimeter method [18], in the preliminary methacholine challenge test. Two of the children subsequently withdrew from the study because of noncompliance. Of the 25 subjects who completed the study, the presumed causes of bronchiectasis were: measles (1 case); tuberculosis (5); ciliary dyskinesis (6); and idiopathic (13). There were no patients with cystic fibrosis, humoral immune deficiency or bronchopulmonary aspergillosis. Nine subjects were atopic, as judged by at least one wheal $>3 \mathrm{~mm}$ on skin-prick test with common airborne allergens. Seven patients had asthma, which was defined by a history of episodes of dyspnoea, cough and wheezing, and either a $>15 \%$ increase in FEV1 after inhaled bronchodilator during the acute episode/stable state, or a spontaneous diurnal variation in peak expiratory flow rate $>20 \%$. These patients were being treated with inhaled $\beta_{2}$-agonist (terbutaline or salbutamol) on an as-needed basis.

All the subjects were in a stable clinical state at the time of study and continued their usual postural drainage routine and other prescribed treatment (chest percussion and vibration, and mucolytics, such as ambroxol or Scarboxymethylcysteine) throughout the study. No other drugs, such as cromolyn sodium or inhaled corticosteroids, had been used. None of the patients had received antibiotics or corticosteroids within 1 month before entering the study. There was no history of upper respiratory tract infection for at least 4 weeks prior to the study. The parents of the patients gave informed consent for the study, and the protocol was approved by the Hospital Ethics Committee.

\section{Methods}

The study was conducted in a double-blind, randomized, placebo-controlled fashion after the preliminary methacholine challenge test. A doctor (not responsible for follow-up or data analysis) was assigned the task of dividing the patients into two groups. After the division, each subject performed the high-dose methacholine inhalation test. Lung function was measured with a computerized spirometer (Microspiro-HI 298, Chest, Japan), and the largest value of the triplicate FEV1 at each timepoint was adopted for analysis. At the time of study, baseline FEV1 was more than $60 \%$ of predicted value [19].

The subjects were studied between October 1995 and February 1996. Inhaled $\beta_{2}$-agonist was withheld for at least 12 hours before each test. High-dose methacholine inhalation tests were carried out using a modification of the method described by CHAI et al. [20]. The concentrations $(0.075,0.15,0.3,0.625,1.25,2.5,5,10$, $25,50,100,150,200 \mathrm{mg} \cdot \mathrm{mL}^{-1}$ ) of methacholine (Sigma Chemical, MO, USA) were prepared with dilution in buffered saline ( $\mathrm{pH}$ 7.4). A Rosenthal-French dosimeter (Laboratory for Applied Immunology, MD, USA), triggered by a solenoid valve set to remain open for $0.6 \mathrm{~s}$, was used to generate the aerosol from a DeVilbiss 646 nebulizer (DeVilbiss, PA, USA), with pressurized air at 20 psi. Each subject inhaled five inspiratory capacity breaths of buffered saline and increasing concentrations of methacholine at $5 \mathrm{~min}$ intervals. This gave an output of $0.009 \pm 0.0014 \mathrm{~mL}(\mathrm{mean} \pm \mathrm{SD})$ per inhalation. FEV1 was measured 60-90 s after each inhalation. 
The inhalation was continued until FEV1 fell by more than $50 \%$ from the postsaline value; or the maximal response plateau was reached; or the highest dose of methacholine had been given. For safety reasons, subjects were given the opportunity to stop the challenge test if they felt too much discomfort. The response was expressed as the percentage fall of FEV1 $(\triangle \mathrm{FEV} 1)$ from mean postsaline value, and was plotted against log cumulative dose of inhaled methacholine expressed as breath units (BU). One BU denotes one inhalation of $1 \mathrm{mg} \cdot \mathrm{mL}^{-1}$ methacholine. The dose-response curves were characterized by their position and maximal response. The position was expressed as the provocative cumulative dose of methacholine producing a 20\% fall in FEV1 (PD20), which was calculated by log-linear interpolation between two adjacent data points. The maximal response was defined as the level of maximal response plateau, by averaging the consecutive points on the plateau or of the last data point of the dose-response curve if a plateau could not be obtained. A maximal response plateau occurred if three or more data points of highest concentrations fell within a 5\% response range [21].

After the initial methacholine test, 14 patients were given $4 \mathrm{mg} \cdot \mathrm{kg}^{-1}$ of roxithromycin (Roussel Uclaf, Paris, France) twice a day, and 13 were given placebo. This dose has been shown to be effective in the treatment of acute exacerbation of bronchiectasis in our clinic, and is also commonly administered for the treatment of acute respiratory infection in the paediatric population [22].

During the treatment period, the patients were assessed by one of the research group every 3 weeks, and FEV1 was measured on each occasion. Sputum was collected on waking each visit day, and was examined for its colour and polymorphonuclear leucocyte (PMN) counts. Sputum colour was noted by the same assessor and classified as follows: mucoid $=1$; mucopurulent $=2$; purulent $=3$. Sputum smears were treated with Wright's stain. An average number of PMNs in three fields at $\times 400$ magnification (high power field (hpf)) was recorded and scored as follows: $<20 \mathrm{PMN} \cdot \mathrm{hpf}^{-1}=1 ; 20-50 \mathrm{PMN} \cdot \mathrm{hpf}^{-1}$ $=2 ;>50$ PMN $\cdot \mathrm{hpf}^{-1}=3$.

A close check was kept on the drug supplies of the patient, and used packets or sachets were checked to monitor compliance. After 12 weeks of treatment, the high-dose methacholine inhalation tests were repeated, and the same parameters were measured as in the initial tests. Roxithromycin was stopped $24 \mathrm{~h}$ before these methacholine inhalation tests.

\section{Statistical analysis}

Mean and standard deviation values were calculated for the variables. All PD20 values were log-transformed before analysis. Analysis of variance (ANOVA) was used to analyse difference in the variables between the two groups. Comparisons of FEV1 between pretreatment and the following visits were analysed for each group, using paired t-tests, while the comparisons of noncontinuous variables (sputum purulence and leucocyte scores) were analysed using Wilcoxon signed rank test. The changes of PD20 or maximal response before treatment compared to after treatment were assessed with paired t-tests. All the analyses were made using StatView II (Abacus Concept Inc., Berkeley, USA) on a Macintosh computer (Apple Computer Inc., Cupertino, USA). A p-value of less than 0.05 was considered statistically significant.

\section{Results}

The high-dose methacholine inhalation tests were well tolerated. Two subjects (one in each group) were withdrawn from the study because of noncompliance with medication or regular check-up. There were no significant differences between the roxithromycin group and the placebo group with respect to age, height, weight, causes of bronchiectasis, or atopy. Three asthmatic patients belonged to the roxithromycin group, and four asthmatics to the placebo group. In the initial methacholine challenge test, three of the roxithromycin group and two of the placebo group did not attain a maximal response plateau. There were no differences in baseline FEV1, PD20 and maximal response to methacholine expressed as the percentage fall in FEV1 $(\Delta \mathrm{FEV} 1, \max )$ between the two groups (table 1).

Table 2 summarizes the changes of FEV1 (\% predicted), sputum purulence and leucocyte scores during the study period, with reference to baseline values. There was no significant change in FEV1 throughout the period in either group. The patients in the roxithromycin group showed a significant improvement in the sputum purulence scores by the sixth week of treatment $(p<0.05)$, which was maintained for the rest of the study period. Sputum leucocyte scores showed a similar trend, in which significant improvements occurred by the sixth week of treatment in the roxithromycin group. The placebo group did not show significant alterations either in sputum

Table 2. - The values of FEV 1 and sputum scores before and during treatment with roxithromycin or placebo

\begin{tabular}{|c|c|c|c|c|c|}
\hline & \multirow[b]{2}{*}{$\begin{array}{l}\text { Before } \\
\text { treatment }\end{array}$} & \multicolumn{4}{|c|}{ Weeks of treatment } \\
\hline & & 3 & 6 & 9 & 12 \\
\hline \multicolumn{6}{|l|}{ FEV1 \% pred } \\
\hline Roxithromycin group & $83 \pm 6$ & $84 \pm 8$ & $84 \pm 7$ & $85 \pm 6$ & $86 \pm 7$ \\
\hline Placebo group & $84 \pm 7$ & $85 \pm 10$ & $85 \pm 8$ & $84 \pm 8$ & $85 \pm 8$ \\
\hline \multicolumn{6}{|l|}{ Sputum purulence score } \\
\hline Roxithromycin group & $2.54 \pm 0.52$ & $2.23 \pm 0.73$ & $1.77 \pm 0.83 *$ & $1.54 \pm 0.66 * *$ & $1.39 \pm 0.65 * *$ \\
\hline Placebo group & $2.42 \pm 0.52$ & $2.50 \pm 0.52$ & $2.17 \pm 0.72$ & $2.08 \pm 0.79$ & $2.17 \pm 0.72$ \\
\hline \multicolumn{6}{|l|}{ Sputum leucocyte score } \\
\hline Roxithromycin group & $2.23 \pm 0.73$ & $2.00 \pm 0.82$ & $1.62 \pm 0.77 *$ & $1.46 \pm 0.66^{*}$ & $1.31 \pm 0.48 * *$ \\
\hline Placebo group & $2.17 \pm 0.83$ & $2.00 \pm 0.74$ & $1.92 \pm 0.79$ & $1.92 \pm 0.79$ & $1.83 \pm 0.83$ \\
\hline
\end{tabular}

Values are presented as mean \pm SD. $*: p<0.05 ; * *: p<0.01$, compared to the value before treatment. For definitions see legend to table 1 . 


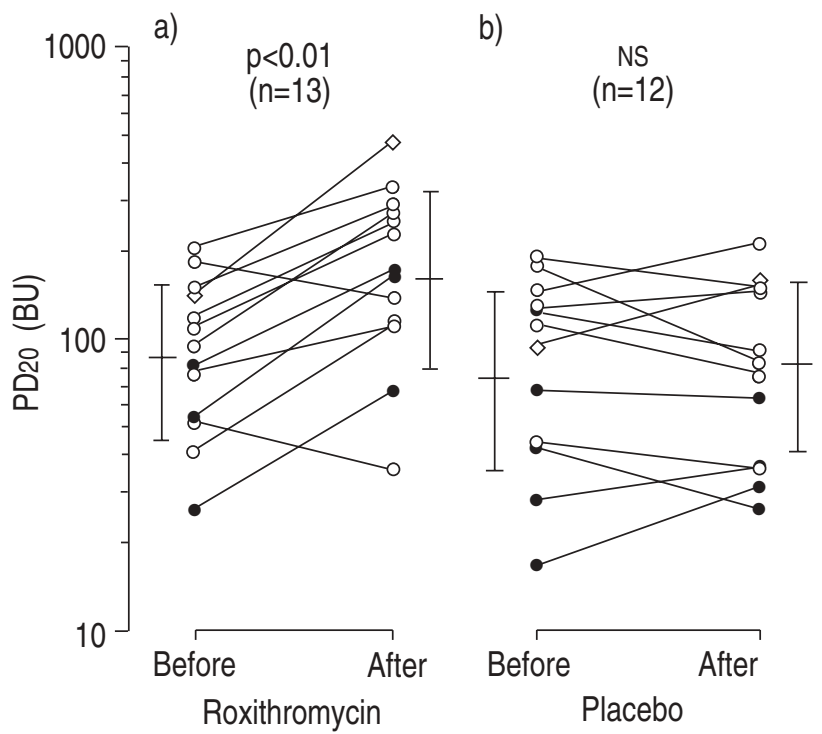

Fig. 1. - a) Individual PD20 values before and 12 weeks after roxithromycin treatment. b) Individual PD20 values before and 12 weeks after placebo treatment. Means and 1 SD are indicated with horizontal bars. $\bullet$ : asthmatic subject; $\diamond:$ atopic nonasthmatic subject; $\bigcirc:$ nonatopic nonasthmatic subject. FEV 1 : forced expiratory volume in one second; PD20: provocative cumulative dose producing a $20 \%$ fall in FEV1; NS: nonsignificant; BU: breath unit (1 BU denotes one inhalation of $1 \mathrm{mg} \cdot \mathrm{mL}^{-1}$ methacholine).

purulence or leucocyte scores throughout the period. All of the patients, with the exception of two in the placebo group, remained clinically stable without any evidence of infective exacerbations. These two patients experienced acute exacerbations, as evidenced by fever, increased cough and sputum production. Sputum cultures recovered Pseudomonas aeruginosa in one case and Haemophilus influenzae in the other. They were prescribed cephalosporin or amoxycillin with clavulanic acid, based on sensitivity tests.

The changes in PD20 for the two groups are depicted in figure 1. In the roxithromycin group, nine subjects showed an increase in PD20 by more than a single twofold dilution of methacholine. All three asthmatics came under this category. In the placebo group, one subject exhibited an increase and one subject a decrease in PD20 by twofold magnitude. None of the four asthmatics showed such a change. In the roxithromycin group, the geometric mean value (range of $1 \mathrm{SD}$ ) of PD20 was significantly increased to $169.2(83.2-344.2)$ BU, compared with that before treatment, $87.1(47.3-160.4)$ BU ( $<<$ 0.01 ) (fig. 1a). The change was not significant in the placebo group, from 74.2 (36.6-150.4) to 82.7 (41.8163.7) BU (p>0.1) (fig. 1b).

The changes of $\triangle F E V 1$, max are presented in figure 2 . Three subjects (one in the roxithromycin group and two in the placebo group) who failed to attain the maximal response plateau both before and after treatment, were excluded from the analysis. In the roxithromycin group, two subjects without the plateau before treatment showed the plateau after treatment, and were included in the analysis. Mean value $( \pm \mathrm{SD})$ of $\triangle \mathrm{FEV} 1$, max was decreased significantly to $32.5( \pm 6.8) \% 12$ weeks after roxithromycin treatment, compared to $40.9( \pm 7.4) \%$ before treatment $(\mathrm{p}<0.01)$ (fig. $2 \mathrm{a})$. The change was not significant in the placebo group, from $36.5( \pm 6.5)$ to $37.2( \pm 6.7) \%$ (p>0.1) (fig. 2b).

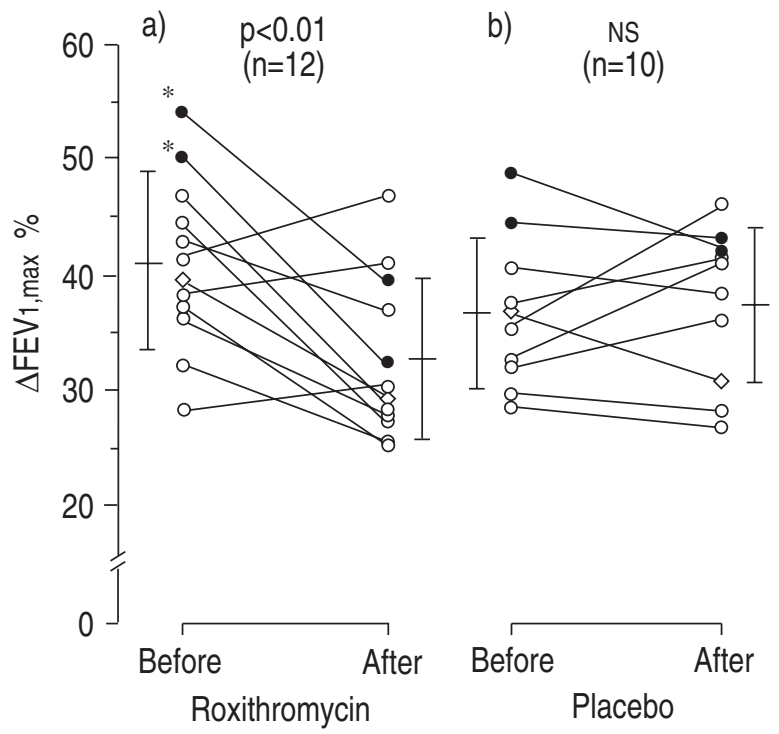

Fig. 2. - a) Individual $\triangle F E V_{1, \max }$ values before and 12 weeks after

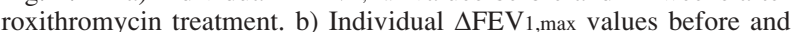
12 weeks after placebo treatment. Means and 1 SD are indicated with horizontal bars. *: subject without maximal response plateau before treatment but with the plateau after treatment; $\bullet$ : asthmatic subject; $\diamond:$ atopic nonasthmatic subject; $\bigcirc$ : nonatopic nonasthmatic subject. NS: nonsignificant; FEV1,max: maximal response to methacholine expressed as the percentage fall in forced expiratory volume in one second.

\section{Discussion}

This study has shown that administration of roxithromycin for 12 weeks reduced bronchial sensitivity and maximal response on the dose-response curve to methacholine in children with bronchiectasis and increased AR. The geometric mean of PD20 increased significantly after the medication, and nine of the 13 patients showed an increase in PD20 of more than a single two-fold dilution of methacholine, a value that is considered to be significant [23]. $\triangle \mathrm{FEV} 1$,max, defined as the level of plateau or maximal percentage fall in FEV1, decreased significantly, despite possible underestimation of the difference. Neither PD20 nor $\triangle F E V 1$, max changed after placebo treatment. The present results indicate that roxithromycin may reduce AHR in patients with bronchiectasis.

Only subjects with increased AR were studied, because our previous investigation had shown that AR was unchanged by roxithromycin in subjects with normal AR [24]. The difference in effect between the subjects with increased and normal AR could be related to the findings that inhaled corticosteroids reduced the maximal response plateau [25] and bronchial sensitivity [26] in asthma, whereas they had no effect on either component in normal subjects [27]. Twelve weeks were chosen for duration of treatment in the present study, because our previous open study [24] indicated that the changes of AR were quite modest after 8 weeks of administration.

AHR has been reported to occur in patients with bronchiectasis [4-6], although the technique of measurement and criteria for AHR has varied among studies. BAHOus et al. [4] noted that $69 \%$ of 29 subjects with bronchiectasis had AHR, and this was significantly related to clinical features of asthma. Others have reported an increased prevalence of AHR to methacholine of 33 and $45 \%$ in adult bronchiectatic subjects $[5,6]$. In the present study, the frequency of increased AR (43\%) 
appears to be comparable to the above results. However, taking account of the higher value of our criteria for increased $\mathrm{AR}\left(\mathrm{PC} 20<25 \mathrm{mg} \cdot \mathrm{mL}^{-1}[18]\right)$ compared to those of other studies $\left(\mathrm{PC}_{20}<5 \mathrm{mg} \cdot \mathrm{mL}^{-1}[5], \mathrm{PC}_{20}<8\right.$ $\left.\mathrm{mg} \cdot \mathrm{mL}^{-1}[6]\right)$, the frequency of increased AR was lower in our study. This may be due to the difference in age of the study population or the technique of measurement of AR (dosimeter method [20] in the present study versus the tidal breathing method [28] in other studies $[5,6])$. Concomitant asthma cannot be the main cause of increased AR in bronchiectatic subjects [4, 29], because the majority of those who were hyperreactive did not fulfil our criteria for asthma.

The present study is the first double-blind, placebocontrolled study of the effects of roxithromycin on AR in patients with bronchiectasis. The effect of roxithromycin is unlikely to result from changes of airway calibre, as no changes in FEV1 were observed during the course of treatment. We do not think that improvement in AR is related to seasonal variation due to allergen avoidance, because the placebo treatment was performed in parallel with the roxithromycin treatment and had no effect on AR. Nonetheless, we cannot rule out the possibility that AR varies over time in patients with bronchiectasis. In fact, two subjects in the placebo group exhibited a significant change in PD20. A time span of 12 weeks without interval challenge results appears long, and interval data on AR would be particularly relevant in view of the fact that FEV1 changes over time were not noted in both groups. Further long-term study on the temporal variation of AR in bronchiectasis is necessary to clarify this point.

The mechanism of action of roxithromycin in reducing AR is not clear. Although the hypersensitivity and augmented maximal response are determined by, at least partially, different mechanisms [17], the two phenomena are both associated with airway inflammation [30]. Therefore, the diminution of bronchial sensitivity and maximal response in this study could be interpreted as a reduction of airway inflammation. It is not possible from this study to establish whether the improvement in $\mathrm{AR}$ is due to an antimicrobial or anti-inflammatory action of roxithromycin. Since persistent airway inflammation in bronchiectasis, which may contribute to AHR [31], results from chronic bacterial sepsis [2, 3], it can be assumed that decreasing the inflammatory load may lead to improvement of AR. A preliminary study by KeLLy et al. [11] showed that intensive antibiotic therapy with amoxycillin decreased PC20 to methacholine in patients with bronchiectasis. Thus, the decrease in AR with roxithromycin could have been simply due to treating infection. Apart from its antimicrobial property, roxithromycin has been reported to have anti-inflammatory actions, such as inhibition of neutrophil chemotaxis [32], or generation of reactive oxygen species by polymorphonuclear leucocytes [14]. It may also have some inhibitory effects on cytokine secretion from leucocytes [33]. Recent studies [13, 34] have reported that roxithromycin could reduce AHR in asthmatic children via its anti-inflammatory action. This may well be the mechanism underlying the beneficial effect of roxithromycin on AR in the present study. Thus, the mechanism of action of roxithromycin may be twofold, i.e. antimicrobial and anti-inflammatory.
It has been suggested that AHR plays a part in the pathogenesis of bronchiectasis by reducing the efficiency of respiratory clearance mechanisms, thereby promoting microbial colonization and inflammation [5]. ELBORN et al. [35] reported that inhaled corticosteroids were of symptomatic benefit in bronchiectasis. They also noted an increase in PC20 histamine by at least one doubling dose in subjects with AHR. However, IP et al. [6] suggested that, in patients with bronchiectasis, AHR was not related to the severity of bronchial sepsis. In the current study, although the decrease in AR in the roxithromycin group paralleled an improvement in sputum features as a whole, it should be noted that some patients had no change in sputum features despite a decrease in $\mathrm{AR}$ and vice versa. Because of the small number of patients studied, the variable baseline conditions of AR and sputum features, and the narrow range of their changes, we did not examine the association between the changes of these parameters. Moreover, it is difficult to estimate the clinical significance of the reduction of AR in bronchiectasis related to antibiotics. Further studies with other medications are needed to clarify these points.

In conclusion, this study has shown that roxithromycin treatment for 12 weeks may decrease the degree of airway responsiveness in children with bronchiectasis who have an increased airway responsiveness. It is not clear whether the decreased airway responsiveness paralleled clinical improvement. Further studies are necessary to determine the mechanisms by which roxithromycin reduces airway responsiveness in bronchiectasis and its clinical impact and on differences in continuous versus intermittent treatment with antibiotics.

Acknowledgement: The authors wish to thank Hoechst-Marion-Roussel Korea Ltd, Seoul, Korea for providing the placebo preparations.

\section{References}

1. Stillwell PC. Bronchiectasis. In: Loughlin GM, Eigen $\mathrm{H}$, eds. Respiratory Disease in Children. Diagnosis and Management. Baltimore, Williams and Wilkins, 1994; pp. 307-314.

2. Cole PJ. A new look at the pathogenesis and management of persistent bronchial sepsis: a "vicious circle" hypothesis and its logical therapeutic connotations. In: Davies RJ, ed. Strategies in the Management of Chronic Bronchial Sepsis. Oxford, Medicine Publishing Foundation, 1984; pp. 1-16.

3. Cole PJ. Inflammation: a two-edged sword, the model of bronchiectasis. Eur J Respir Dis 1986; 69 (Suppl. 147): 6-15.

4. Bahous J, Cartier A, Pineau L, et al. Pulmonary function tests and airway responsiveness to methacholine in chronic bronchiectasis of the adult. Bull Eur Physiopathol Respir 1984; 20: 375-380.

5. Pang J, Chan HS, Sung JY. Prevalence of asthma, atopy, and bronchial hyperreactivity in bronchiectasis: a controlled study. Thorax 1989; 44: 948-951.

6. Ip M, Lam WK, So SY, Liong E, Chan CY, Tse KM. Analysis of factors associated with bronchial hyperreactivity to methacholine in bronchiectasis. Lung 1991; 169: 43-51. 
7. Ip M, Shum D, Lauder I, Lam WK, So SY. Effect of antibiotics on sputum inflammatory contents in acute exacerbations of bronchiectasis. Respir Med 1993; 87: 449-454.

8. Cole PJ, Roberts DE, Davies SF, Knight PK. A simple oral antimicrobial regimen effective in severe chronic bronchial suppuration associated with culturable Haemophilus influenzae. J Antimicrob Chemother 1983; 11: 109-113.

9. Hill SL, Morrison HM, Burnett D, Stockley RA. Shortterm response of patients with bronchiectasis to treatment with amoxycillin given in standard or high doses, orally or by inhalation. Thorax 1986; 41: 559-565.

10. Hill SL, Burnett D, Hewetson KA, Stockley RA. The response of patients with purulent bronchiectasis to antibiotics for four months. $Q$ J Med 1988; 66: 163 173.

11. Kelly CA, Stenton C, Gould K, Hendrick DJ. The effect of high-dose amoxycillin on bronchial responsiveness and symptoms in patients with bronchiectasis. Am Rev Respir Dis 1987; 135: A269.

12. Miyatake H, Taki F, Taniguchi H, Suzuki R, Takagi K, Satake T. Erythromycin reduces the severity of bronchial hyperresponsiveness in asthma. Chest 1991; 99: 670673.

13. Shimizu T, Kato M, Mochizuki H, Tokuyama K, Morikawa A, Kuroume T. Roxithromycin reduces the degree of bronchial hyperresponsiveness in children with asthma. Chest 1994; 106: 458-461.

14. Labro MT, Benna JE, Babin-Chevaye C. Comparison of the in vitro effect of several macrolides on the oxidative burst of human neutrophils. J Antimicrob Chemother 1989; 24: 561-572.

15. Holgate ST, Beasley R, Twentyman OP. The pathogenesis and significance of bronchial hyperresponsiveness in airway disease. Clin Sci 1987; 73: 561-572.

16. Woolcock AJ, Salome CM, Yan K. The shape of the dose-response curve to histamine in asthmatic and normal subjects. Am Rev Respir Dis 1984; 130: 71-75.

17. Sterk PJ, Bel EH. Bronchial hyperresponsiveness: the need for a distinction between hypersensitivity and excessive airway narrowing. Eur Respir J 1989; 2: 267274.

18. Shapiro GG, Furukawa CT, Pierson WE, Bierman CW. Methacholine bronchial challenge in children. $J$ Allergy Clin Immunol 1982; 69: 365-369.

19. Yoon KA, Lim HS, Koh YY, Kim H. Normal predicted values of pulmonary function tests in Korean school-aged children. J Korean Pediatr Assoc 1993; 36: 25-37.

20. Chai H, Farr RS, Froelich LA, et al. Standardization of bronchial inhalation challenge procedures. J Allergy Clin Immunol 1975; 56: 323-327.

21. Sterk PJ, Timmers MC, Dijkman JH. Maximal airway narrowing in humans in vivo: histamine compared with methacholine. Am Rev Respir Dis 1986; 134: 714-718.
22. Bazet MC, Blanc F, Chumdermpadetsuk S, et al. Roxithromycin in the treatment of paediatric infections. $\mathrm{Br}$ J Clin Pract 1988; 42 (Suppl. 55): 117-118.

23. Juniper EF, Frith PA, Dunnett C, Cockcroft DW, Hargreave FE. Reproducibility and comparison of responses to inhaled histamine and methacholine. Thorax 1978; 33: 705-710.

24. Koh YY, Lee MH, Yoon KA, Seoung GW. The effect of roxithromycin on the bronchial responsiveness in children with bronchiectasis. Pediatr Allergy Respir Dis (Korean) 1996; 6: 74-85.

25. Bel EH, Timmers MC, Zwinderman AH, Dijkman JH, Sterk PJ. The effect of inhaled corticosteroids on the maximal degree of airway narrowing to methacholine in asthmatic subjects. Am Rev Respir Dis 1991; 143: 109-113.

26. Kerrebijn KF, van Essen-Zandvliet EEM, Neijens HJ. Effect of long-term treatment with inhaled corticosteroids and $\beta$-agonists on the bronchial responsiveness in children with asthma. J Allergy Clin Immunol 1987; 79: 653-659.

27. Bel EH, van der Veen H, Dijkman JH, Sterk PJ. The effect of inhaled budesonide on the maximal degree of airway narrowing to leukotriene $\mathrm{D}_{4}$ and methacholine in normal subjects in vivo. Am Rev Respir Dis 1989; 139: 427-431.

28. Cockcroft DW, Killian DN, Mellon JJA, Hargreave FE. Bronchial reactivity to inhaled histamine: a method and clinical survey. Clin Allergy 1977; 7: 235-243.

29. Murphy MB, Reen DJ, Fitzgerald MX. Atopy, immunological changes and respiratory function in bronchiectasis. Thorax 1984; 39: 179-184.

30. Boonsawat W, Salome CM, Woolcock AJ. Effect of allergen inhalation on the maximal response plateau of the dose-response curve to methacholine. Am Rev Respir Dis 1992; 146: 565-569.

31. Boushey HA, Holtzman MJ, Sheeler JR, Nadel JA. State of art: bronchial hyperreactivity. Am Rev Respir Dis 1980; 121: 389-408.

32. Anderson R. Erythromycin and roxithromycin potentiate human neutrophil locomotion in vitro by inhibition of leukoattractant-activated superoxide generation and auto-oxidation. J Infect Dis 1989; 159: 966-973.

33. Konno S, Asano K, Kurokawa M, Ikeda K, Okamoto $\mathrm{K}$, Adachi M. Antiasthmatic activity of a macrolide antibiotic, roxithromycin: analysis of possible mechanisms in vitro and in vivo. Int Arch Allergy Immunol 1994; 105: 308-316.

34. Kamoi H, Kurihara N, Fujiwara H, Hirata K, Takeda T. The macrolide antibacterial roxithromycin reduces bronchial hyperresponsiveness and superoxide anion production by polymorphonuclear leukocytes in patients with asthma. J Asthma 1995; 32: 191-197.

35. Elborn JS, Johnston B, Allen F, Clarke J, McGarry J, Varghese G. Inhaled steroids in patients with bronchiectasis. Respir Med 1992; 86: 121-124. 